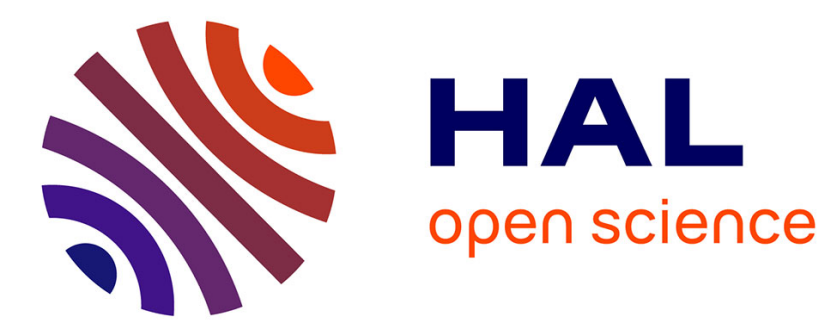

\title{
Stress and recovery assessment during simulated microgravity: Effects of exercise during a long-term head down tilt bed rest in women.
}

Weiss Karine, Michel Nicolas

\section{- To cite this version:}

Weiss Karine, Michel Nicolas. Stress and recovery assessment during simulated microgravity: Effects of exercise during a long-term head down tilt bed rest in women.. Journal of Environmental Psychology, 2009, 29(4), pp.522-528. halshs-00510437

\section{HAL Id: halshs-00510437 \\ https://shs.hal.science/halshs-00510437}

Submitted on 27 Apr 2011

HAL is a multi-disciplinary open access archive for the deposit and dissemination of scientific research documents, whether they are published or not. The documents may come from teaching and research institutions in France or abroad, or from public or private research centers.
L'archive ouverte pluridisciplinaire HAL, est destinée au dépôt et à la diffusion de documents scientifiques de niveau recherche, publiés ou non, émanant des établissements d'enseignement et de recherche français ou étrangers, des laboratoires publics ou privés. 


\title{
Stress and recovery assessment during simulated microgravity: Effects
} of exercise during a long-term head-down tilt bed rest in women

\author{
Michel Nicolas, Karine Weiss
}

\begin{abstract}
The aim of this study was to determine the effects of a 60-day head-down tilt long-term bed rest (HDT) on stress and recovery in sixteen healthy female volunteers. Participants were randomly assigned to either an exercise group (Exe) that followed a training program combining resistive and aerobic exercises, or to a no-exercise control group (Ctl). Psychological states were assessed using the Rest$Q$, a validated questionnaire based on stress-recovery responses. A longitudinal analysis revealed significant changes in the general and specific-stress scales for all participants throughout the experiment with a critical stage from supine to standing posture leading to a significant decrease in physical recovery. During HDT, Exe reported higher scores on stress subscales, as well as lower recovery scores compared to the Ctl. During the post-HDT ambulatory recovery period, the exercisers still reported higher scores than the non-exercisers on the Lack of energy stressrelated scale, along with lower scores in general wellbeing and personal accomplishment. The present findings show that simulated weightlessness such as HDT may induce psychological stress and lead to subsequent alterations in perceived recovery. Exercise did not reduce HDT impaired effects on stress and recovery states. Several suggestions, including psychological preparation, are proposed to support the beneficial effects of exercise on psychological factors.
\end{abstract}

\section{Keywords:}

Bed rest ; Exercise countermeasures ; Recovery ; Space simulation ; Stress

Manned spaceflights can be defined as an extreme environment because of the high level of constraints linked to numerous unfamiliar conditions including microgravity, monotony, lack of comfort, boredom, confinement and isolation (Kanas \& Manzey, 2003; Suedfeld, 2005). Most of these constraints are present in space simulation experiments such as long-term bed rest (LTBR) which can also be considered as an extreme environment. LTBR not only constitutes a validated physiological model of spaceflights (e.g. Lathers \& Charles, 1994; Louisy, Berry, Marini, Guell, \& Guezennec, 1995; Sonnenfeld et al., 2007), but also provides good psychological analogues (Weiss \& Moser, 1998). LTBR is typified by "deprivation including the lack of customary amenities, isolation from the home community, confinement with a relatively small number of other people, lack of privacy, difficult and demanding tasks, limited opportunities for communication, and a degree of dependence on outsiders" (Harrison, 2005). Previous investigations have shown that simulated microgravity, along with immobilization in bed, accompanied by environmental constraints, induced disorders in psychological states such as an increase in depressive and neurotic levels (Ishizaki et al., 1994; Styf, Hutchinson, Carlsson, \& Hargens, 2001). During LTBR, people have to face environmental changes which might involve possible adverse effects including the development of 
stress responses (Gushin, 1995), and side effects ranging from a failure to recover to burnout and pathological disorders. It seems that simulating weightlessness induces psychological stress (Chouke`r et al., 2001; Grigor'ev \& Fedorov 1996; Ishizaki et al., 2002). On the other hand, studies of such analogue environments have shown processes linked to adaptation to environmental constraints (Kanas \& Manzey, 2003; Ritsher, Kanas, Ihle, \& Saylor, 2007). Consequently, bed rest studies in healthy volunteers provide a unique opportunity to examine the time-course of these stress and recovery states and the effect of exercise on these psychological variables. Moreover, gender differences appear within the coping processes in extreme situations, especially because men and women do not use social support and emotional coping in the same way (Leon, 2005; Rosnet, Jurion, Cazes, \& Bachelard, 2004). Gender studies are still rare because the presence of female crewmembers in extreme situations is quite recent, even if teams for future longterm manned spaceflights such as missions to Mars will surely be mixed-gender ones. If stress responses have been well-documented in space missions and simulations (Suedfeld, 2005), recovery has been a neglected phenomenon up until now although it is a significant dimension linked to required performances in extreme situations.

Most of the studies have addressed stress responses with indicators which evaluate either the evolution of mood states or coping strategies. However, recovery can also play a considerable role in the well-being of the participants as well as in their performances. A lack of recovery can interfere with performance and also induce emotional, cognitive and behavioral disturbances, which can lead to psychological exhaustion and thus compromise the participants' adaptation to environmental constraints (Kellmann \& Günther, 2000; Kellmann, Kallus, Steinacker, \& Lormes, 1997). Hence, as a major point in the stress process, great importance should be given to monitoring both stress and recovery. Adjustment and performance are achievable if participants are able to recover and to find a balance between stress workload and adequate recovery (Rowbottom, Keast, \& Morton, 1998). Different studies reported that psychologically related stress and recovery were good indicators of clinical states and biological measures such as metabolic

and hormonal concentrations (Filaire, Bernain, Sagnol, \& Lac, 2001; Kellmann et al., 1997; Steinacker et al., 2000). Findings in both women and men in the general population indicate that positive affective responses are experienced by exercisers after relatively short bouts of acute exercise, and that these positive effects can still be obvious over the long term (Daley \&Welch, 2004; Hansen, Stevens, \& Coast, 2001; O'Halloran, Kirkby, \& Webster, 2001; Parfitt \& Gledhill, 2004). Even if several studies have found that physical exercise reduced psychological stress in

gravitational situations (Nabkasorn et al., 2006; Otto,1990; Salmon, 2001), other studies in simulated microgravity found more controversial results. For instance, a bed rest study (Ishizaki et al., 2002) showed that some negative changes related to mood states appeared during a 20-day head-down tilt bed rest (HDT), and these adverse effects were not compensated by isometric exercise training. In another bed rest study (DeRoshia \& Greenleaf, 1993), few deleterious changes in performance and mood occurred among the participants compared to baseline ambulatory levels. In addition, the Exe group was distinguished from the Ctl group by a decline in the activation mood dimension and in two of its constituent scales (motivation and concentration), and by improvement in the trouble-falling-asleep and psychologicaltension scales. Nevertheless, the authors concluded that moods and performances were not impaired in response to LTBR and were not changed by exercise training. The present investigation is one of the first to explore stress and 
recovery in healthy women in a 60-day HDT. If women currently represent a small percentage of space travelers, this percentage should increase in future long duration spaceflights. Consequently, it is of prime importance to improve knowledge of gender-specific differences. The aim of this study was to determine (1) if several dimensions of stress occur in healthy women during LTBR, (2) the time-course of stress states in parallel with recovery states, and (3) the effects of an exercisetraining program on these psychological variables. Based on the previous findings, the following hypotheses were made: (i) All the participants would report changes in stress and recovery levels throughout the experiment and across the different phases; (ii) These changes would show opposite results for the Ctl and the Exe groups. The $\mathrm{Ctl}$ group would indicate increased levels in stress and decreased levels in recovery factors during HDT. On the contrary, exercisers would report decreased levels on stress scales and increased levels on recovery scales during HDT.

\section{Methods}

\subsection{Context and participants}

The participants represented a wide range of nationalities including Czech, Dutch, French, English, Finish, Polish, Scottish, German and Swiss. The candidates were selected based on lifestyle, education, professional and medical information combined with medical and psychological examinations. All subjects had to be

physically active with correct aerobic fitness (mean_SD, VO2max [maximum amount of oxygen] 39_4 $\mathrm{ml} / \mathrm{kg} / \mathrm{min}$ ), but competitive athletes were excluded. All women had a regular menstrual cycle, and oral contraceptionwas stopped at least two months before the beginning of bed rest. Tobacco, coffee, tea and alcohol were prohibited during the stay at the clinic. Inclusion criteria for the subjects included non-smokers prior to the experiment, free of clinical or biomedical diseases, did not take any medications and did not experience major stressful life situations 2 months prior to the study, no family history of chronic or acute diseases, and free from orthopedic, musculoskeletal and cardiovascular disorders. The WISE-2005 study (Women International Space Simulation for Exploration) was designed in order to simulate a space mission with long-term anti-orthostatic bed rest at _6_ involving healthyfemale volunteers. After the selection process, the participants received verbal and written explanations about the study objectives, procedures and potential risks of the experimentation. The 16 women selected (32_4 yrs; $56.4 \_3.6 \mathrm{~kg} ; 164$ _ $8 \mathrm{~cm}$; mean _SD) gave written informed consent for participating in this study. The subjects underwent uninterrupted anti-orthostatic bed rest for a 60-day duration. The experiment consisted of three stages: a 20-day baseline control period (BDC), a 60day head-down tilt bed rest (HDT) and a 20-day post-HDT ambulatory recovery period $(\mathrm{Rp})$. The participants were randomly assigned to either a noexercise control group (Ctl, $n{ }^{1 / 4} 8$ ) or an exercise countermeasure group (Exe, $n^{1 / 4} 8$ ). All the participants received medical and psychological support throughout the experiment.

\subsection{Procedure and experimental design}

The duration of the training program was $10 \mathrm{~h}$ a week and combined two types of exercises done while lying down: an aerobic exercise and a resistive one. These two types of exercises were never done on the same day. During the HDT period, daily training for the Exe group consisted of exercises at $85 \mathrm{VO} 2 \mathrm{max}$ (165 min per 
day) and of exercises from the anaerobic threshold to VO2max (45 min per day). The aerobic lower-body negative pressure (LBNP) treadmill exercise countermeasure consisted of a $40 \mathrm{~min}$ interval $(40-80 \%$ pre-BR VO2pk, peak oxygen uptake measurement) LBNP exercise protocol while lying down, with the lower part of the body in a chamber in which a negative pressure simulated the upright position and the redistribution of blood and fluids (Cao et al., 2005). This exercise was followed by 10 min of resting LBNP immediately after the run. A session was scheduled every three-four days/week for a total of 29 sessions during HDT. Resistance exercise consisted of maximal concentric and eccentric supine leg press and heel raise

exercises using a gravity-independent fly-wheel ergometer 2-3 days/wk-1. The protocol was described earlier (Trappe et al., 2004). After an initial warm-up and stretching period lasting 10-15 min, the subjects did 4 sets of 7 maximal concentric and eccentric squat exercises followed by 4 sets of maximal concentric and eccentric calf press exercises. Each session lasted for about $30 \mathrm{~min}$ and took place every third day. Psychological measures were taken twice at the baseline (BDC _19, _3), three times during head-down tilt bed rest (HDT 10, 29, 43), and 2 times during ambulatory recovery period $(\mathrm{R} p 3, \mathrm{p} 19)$. Data collection also involved one last follow-up measure (R p45).

\subsection{Measures}

The Recovery-Stress Questionnaire for Athletes (RESTQ-Sport) (Kellmann \& Kallus, 2001) was used to assess the balance of stress-recovery states. The recoverystress questionnaire (the RestQsport) is a recent tool for evaluating both stress and recovery states using multidimensional dimensions dealing with psychological, emotional, cognitive and behavioral performance, and physical and social aspects (Kellmann \& Kallus, 2001). On one hand, recovery-stress states indicate the extent to which an individual is physically and/or mentally stressed, and on the other hand, if that individual is able to use individual recovery strategies, and which ones.

Psychometric properties are well-documented in the manual (Kellmann \& Kallus, 2001). Factorial analyses, tests of reliability and validity ensured the fulfillment of psychometric requirements both in female and male junior and senior participants. Previous longitudinal findings have indicated that this questionnaire is a precise monitor of stress and recovery processes (Johnson, Wrisberg, Kellmann, \& Kallus, 1997; Kellmann \& Gu“" nther, 2000; Kellmann \& Kallus, 1993; Kellmann et al., 1997).

The questionnaire is constructed in a modular way and includes 12 scales from the general Recovery-Stress Questionnaire and seven additional exercise-specific scales. The version used in the present study consisted of 77 items (19 scales with four items each plus one warm-up item; see Table 1). As shown in Table 1, the Rest$Q$ was developed with general dimensions concerning stress and recovery as well as with specific dimensions which aim at addressing more details of the stress and recovery processes in sport or physical activity (Kellmann \& Kallus, 2001). A Likerttype scale is used with values ranging from 0 (never) to 6 (always) indicating how often the respondent participated in various activities during the preceding three days and nights. High scores on the stress-associated activity scales reflect intense subjective strain. In addition, high scores on the recovery-oriented scales reveal adequate recovery activities. Some items were adapted for this study to the specificity of the situation; consequently the word "sport" was replaced by "activity" or "experimentation" (e.g. "I felt burned out by my activities" instead of "I felt burned out by my sport" or "I felt frustrated by the experimentation" instead of "I felt 
frustrated by my sport"). An average score on the stress-related scales including both general and specific scales was calculated. The average recovery score was also calculated for the recoveryoriented scales. The French version of the RestQ-Sport has adequate $24 \mathrm{~h}$ test-retest reliability (Chatelier, 2003). This version has shown values of Cronbach's alpha ranging from 0.71 to 0.87 (Filaire et al., 2001).

\subsection{Statistical analysis}

Given that the sample size was small (8 participants per group), and the scores of some factors were not normally distributed, the data were analyzed using nonparametric statistics. Changes in stress-recovery states were assessed first using Friedman's test (F-test) one-way analysis of variance, a repeated measures ANOVA by rank. If differences were detected, the Wilcoxon signed-rank paired t-test was applied in an attempt to determine which specific values were significantly different. Post-hoc comparisons were made using the Mann-Whitney U-test for each stage to determine differences between the Exe and the Ctl groups. Multiple comparisons were conducted with Bonferroni corrections and the alpha level of 0.003 was considered significant. All values in the text are presented as means and standard deviations.

\section{Results}

The WISE-2005 experiment was conducted successfully with the exercisers showing satisfactory tolerance for the exercise countermeasure, and with no major medical problems or psychological disorders for all the participants. All the volunteers completed the HDT period. A participant from the Exe group withdrew from the study during the recovery period (at R p9) for personal reasons. However, she came back for the follow-up assessments. One out of the 8 subjects in the Exe and the Ctl group was considered to be oligomenorrhea (menstrual cycle length longer than 45 days) at the end of the bed rest period. However, the Exe group did not show a significant increase in the duration of the menstrual cycle compared to the pre-bed rest period. Participants in the exercise group completed an average of more than $95 \%$ of the prescribed exercise sessions. No subject completed less than $90 \%$ of her sessions. The internal consistency of the stress-recovery scores was examined using Cronbach's alpha coefficient and was deemed acceptable with a between 0.75 and 0.87 for all of the scales.

\subsection{Global changes in stress-recovery scales over time}

The average score on the general stress scale (F-test, Chi2 1/4 23.32, $p<0.001$, see Fig. 1) indicated a significant variation throughout the experiment for all the participants. This change was confirmed for the average score on specific-stress scales that revealed a significant variation throughout the entire experiment for all the participants (F-test, Chi2 1/425.77, p 1/40.0005). The other variations that affected all the participants only occurred during specific stages of the experiment. During HDT, general stress changed significantly for all the participants (F-test, Chi2 1/424.69, p $<0.001$ ). Analyses of the significant differences between evaluations indicated that the critical stage was the standing up period, at the beginning of the recovery phase. Significant increases were found for all the participants between the first baseline evaluation (BDC_19) and the first recovery evaluation (R p3) for general stress (W- 
test, $Z 1 \frac{1}{4}$ 2.93, $\mathrm{p}^{1 / 4}$ 0.003) and injury (W-test, $Z 1 \frac{1}{4}$ 2.92, $\mathrm{p} 1 / 40.003$, see Fig. 2). Furthermore, during the transitional phase from supine to standing posture, between the last evaluation of HDT (HDT 43) and the first evaluation of the recovery phase (R p3), a significant decrease appeared for physical recovery for all the participants (Wtest, Z 1/43.04, p 1/4 0.002).

Table 1

Dimensions and scales of the Rest-Q Sport (Kellman \& Kallus, 2000).

\begin{tabular}{|c|c|}
\hline \multirow[t]{2}{*}{ Dimension (number of scales) } & Scale \\
\hline & Description \\
\hline General stress (7 scales) & $\begin{array}{l}1 \text { - General stress } \\
\text { Unspecific strain reactions } \\
2 \text {-Emotional stress } \\
\text { Anxiety, in hibitions and anger } \\
3 \text { - Social stress } \\
\text { Frequency of arguments, fights, irritation } \\
\text { concerning others and being upset } \\
4 \text { - Conflicts/pressure } \\
\text { Unsettled conflicts, unpleasant things and } \\
\text { repetitive thoughts } \\
5 \text { - Fatigue } \\
\text { Disturbed work, overfatigue and overcharge } \\
6 \text { - Lack of energy } \\
\text { Deficiency in concentration, energy and } \\
\text { decision-making } \\
7 \text { - Somatic Complaints } \\
\text { Physical indisposition and physical complaints }\end{array}$ \\
\hline General recovery ( 5 scales) & $\begin{array}{l}\mathbf{8} \text { - Success } \\
\text { Success related to performance in general } \\
\mathbf{9} \text { - Social Relaxation } \\
\text { Frequency of pleasurable social contacts, change } \\
\text { combined with relaxation and amusement } \\
\mathbf{1 0} \text { - Somatic Relaxation } \\
\text { Physical relaxation and fitness } \\
\mathbf{1 1} \text { - General Well-being } \\
\text { Frequency of good mood and high } \\
\text { level of well-being } \\
\mathbf{1 2}-\text { Sleep } \\
\text { Trouble in falling asleep and interrupted sleep }\end{array}$ \\
\hline Specific stress ( 3 scales) & $\begin{array}{l}\text { 13- Disturbed breaks } \\
\text { Defective recovery, pauses disturbed by } \\
\text { situational aspects including other people } \\
14 \text { - Burnout/Emotional exhaustion } \\
\text { Burnout, desire to quit } \\
\text { 15 - Fitness/mjury } \\
\text { Acute injury or vulnerability to injuries }\end{array}$ \\
\hline Specific recovery ( 4 scales) & $\begin{array}{l}16 \text { - Fitness/being in shape } \\
\text { Fitness, physical efficiency and vitality } \\
17 \text { - Burnout/personal accomplishment } \\
\text { Feeling of integration in a team, good } \\
\text { communication with teammates and } \\
\text { enjoyment in daily activities } \\
18 \text { - Self-efficacy } \\
\text { Feeling of being well trained and } \\
\text { optimally prepared } \\
19 \text { - Self-regulation } \\
\text { Use of mental skills to prepare, push, } \\
\text { motivate and set goals }\end{array}$ \\
\hline
\end{tabular}

\subsection{Difference between control and exercise groups}

During BDC, the first baseline measure assessment (BDC_19) 
indicated no difference between the groups. For the second evaluation at BDC _3, after the first exercise trainings for the Exe group, the Ctl group reported higher scores than the Exe group for self-efficacy (U-test, $p<0.003$, see Table 2 and Fig. 3). During HDT, the Exe group had significantly higher scores than the Ctl group on the stress-related scales (see Table 2). The Exe group had significantly higher scores than the Ctl group for injury (HDT 29: U-test, $p$ 1/40.001; HDT 43: U-test, $p<0.002$ ) and fatigue (HDT 43: U-test, $p$ 1/40.0006, see Fig. 4). Furthermore, the Ctl group had significantly higher scores than the Exe group on recovery related scales, selfefficacy (HDT 10: U-test, $p$ 1/4 0.003), and being in shape (HDT 29: U-test, $p{ }^{1 / 40.003) . ~ A l l ~ t h e ~}$ significant differences were shown by higher scores on stress dimensions, and lower scores on recovery dimensions for the Exe group compared to the Ctl group. During the ambulatory recovery phase ( $\mathrm{Rp})$, the same trend as in the previous period could be observed, all the differences were still shown by greater experienced stress and lower recovery scores for exercisers than for the non-exercisers (see Table 2). The Exe group had significantly higher scores than the Ctl group on the Lack of energy stress-related scale ( $R$ p19: U-test, $p$ 1/4 0.003). Conversely, for the follow-up assessment, the Ctl group reported higher scores than the Exe group on recovery related scales, general well-being $(R$ p19: U-test, $p<0.001)$ and personal accomplishment ( $R$ p45: U-test, $p<0.002$, see Fig. 5).

\subsection{Interaction effects (time_ groups)}

Some interaction effects between time and groups can be observed, implying exclusively specific evolutions for the Exe group. First, the average score on the stress-related scales including general and specific scales indicated a significant variation throughout the experimentation for the Exe group ( $F$-test, Chi21/4 25.78, $p$ $<0.001)$. In the sameway, during HDT, conflict/pressure varied exclusively for the 


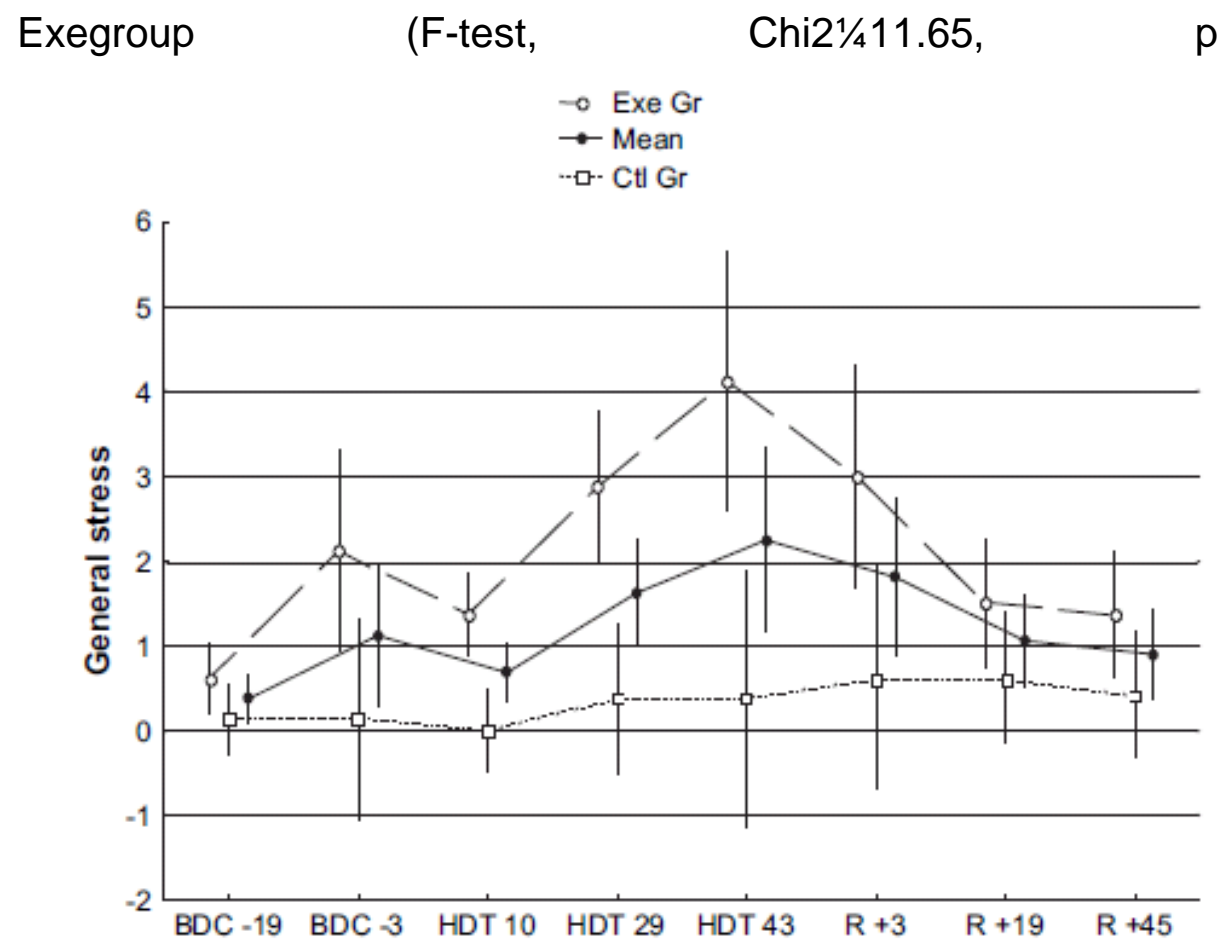

Fig. 1. Time-course of levels of general stress for all participants and both groups throughout the experiment and during the different periods (e.g. BDC, HDT and recovery).

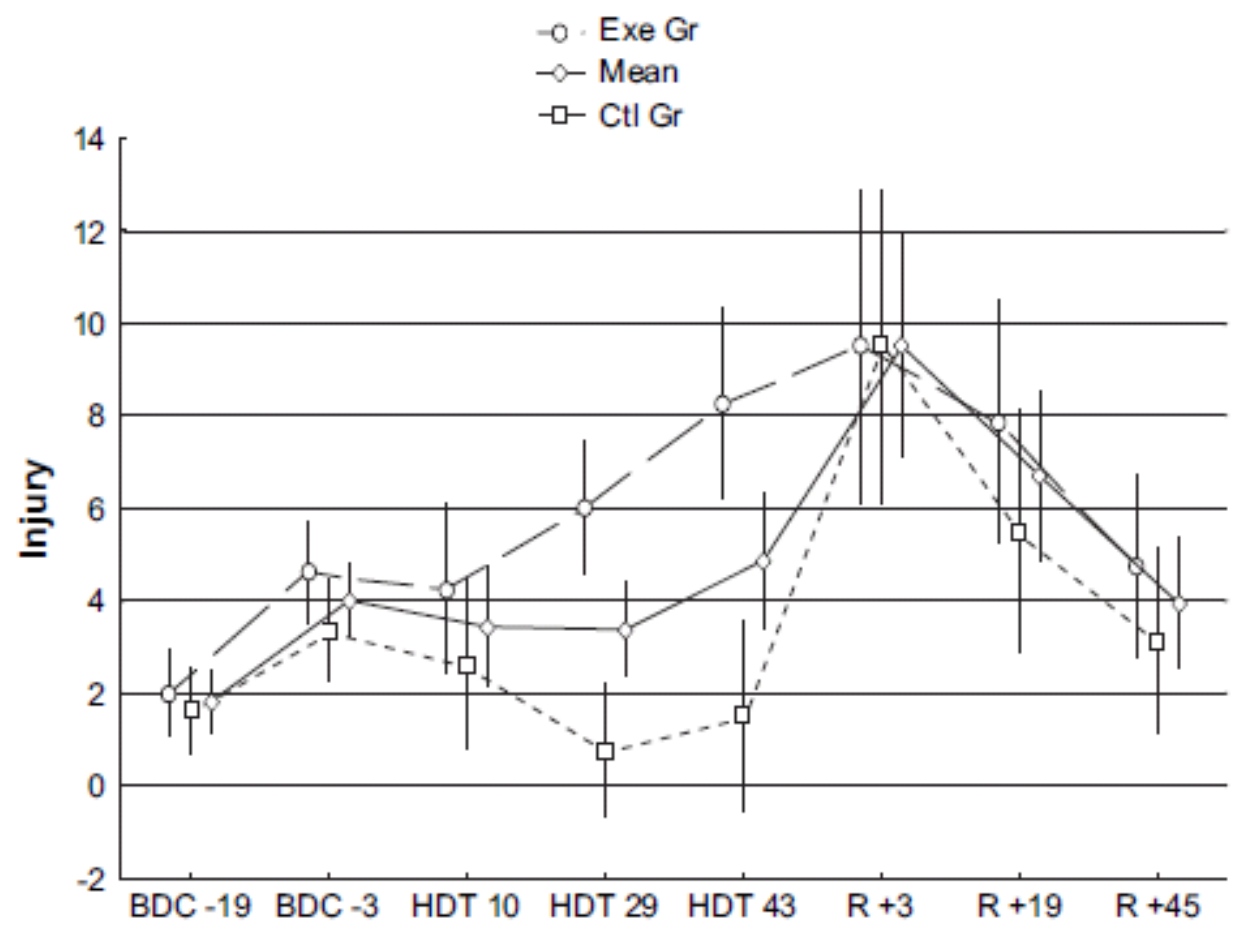

Fig. 2. Time-course of levels of injury for all participants and both groups throughout the experiment and during the different periods (e.g. BDC, HDT and recovery). 
Table 2

Significant differences between the exercise and control groups during BDC, HDT and recovery periods (Recovery scales in italic).

\begin{tabular}{llllll}
\hline $\begin{array}{l}\text { Time } \\
\text { measure }\end{array}$ & Scale & \multicolumn{2}{l}{$\begin{array}{l}\text { Rank Sum } \\
\text { Exe group (8) }\end{array}$} & $\begin{array}{l}\text { Rank Sum } \\
\text { Ct group (8) }\end{array}$ & $\begin{array}{l}\text { adjusted } p \text { value } \\
2 \times(1-p)\end{array}$ \\
\hline BDC -3 & Self-efficacy & 41.5 & 94.5 & -2.79 & 0.003 \\
HDT10 & Self-efficacy & 41 & 95 & -2.84 & 0.003 \\
HDT 29 & Injury & 97 & 39 & 3.11 & 0.001 \\
& Being in shape & 41.5 & 94.5 & -2.79 & 0.003 \\
HDT 43 & Fatigue & 97.5 & 38.5 & 3.15 & 0.0006 \\
& Injury & 95.5 & 40.5 & 2.94 & 0.002 \\
$\mathrm{R}+19$ & Lack of energy & 94.5 & 41.5 & 2.81 & 0.003 \\
& General well-being & 39.5 & 96.5 & -3 & 0.0001 \\
$\mathrm{R}+45$ & $\begin{array}{l}\text { Personal } \\
\text { accomplishment }\end{array}$ & 40.5 & 95.5 & -2.90 & 0.002 \\
\hline
\end{tabular}

\section{Discussion}

The aim of this study was on one hand, to study the psychological effects of a HDT LTBR and, on the other hand, to examine the effects of exercise on the psychological states of the participants. Several findings of the present study are noteworthy. These findings are threefold. (I) As expected, by pointing out the difficulty of such environmental conditions involving immobilization, isolation and confinement, the present results suggest that LTBR HDT exposure may induce stress overload. (II) However, these alterations in psychological states provoked by HDT were not improved by exercise. Somewhat surprisingly and contrary to our hypothesis, the Exe group indicated an increase in the stress level and a decrease in the recovery level compared to their baseline values and to the Ctl group. These changes were particularly clear during HDT and the ambulatory recovery phases with increases on several stress scales for the Exe group. (III) Further information in the present study concerns recovery which is investigated less specifically in these environmental conditions. Participants who followed the exercise program reported less recovery than participants without exercise both during and after HDT. Longitudinal analyses clearly revealed that the average of the general stress scales varied significantly across the phases for all the participants throughout the experimentation. Likewise, the average of the specific-stress scales related to fitness and physical aspects indicated significant changes for all participants and both groups. The findings of the present study support a previous investigation which has clearly shown the negative effects of a HDT LTBR on a series of psychological states (Ishizaki et al., 1994). Our data further confirm previous experiments that have reported that simulating weightlessness induces psychological stress (Chouke` $r$ et al., 2001; Grigor'ev \& Fedorov, 1996; Ishizaki et al., 2002), and show the potential stress of simulated weightlessness even if stress is not inherent in such a situation in particular (Grigor'ev \& Fedorov, 1996) or in other extreme situations such as simulated high altitude (Nicolas et al., 1999), or polar expeditions (Palinkas \& 
Suedfeld, 2007; Suedfeld, 1998). Undoubtedly, the critical stage is the standing up period at the beginning of the recovery ambulatory phase during which the more prevalent increases were noticed. During the transitional phase from the supine to the standing posture, significant increases occurred for all the participants between the first recovery evaluation (R p3) and the first baseline evaluation (BDC _ 19) for general stress and injury. These increases on stress scales were combined with a significant decrease in physical recovery between HDT 43 and R p3. Thus, for all participants with or without exercise, the transition from a horizontal to a vertical posture is perceived as the most difficult period both for stress and the recovery states.
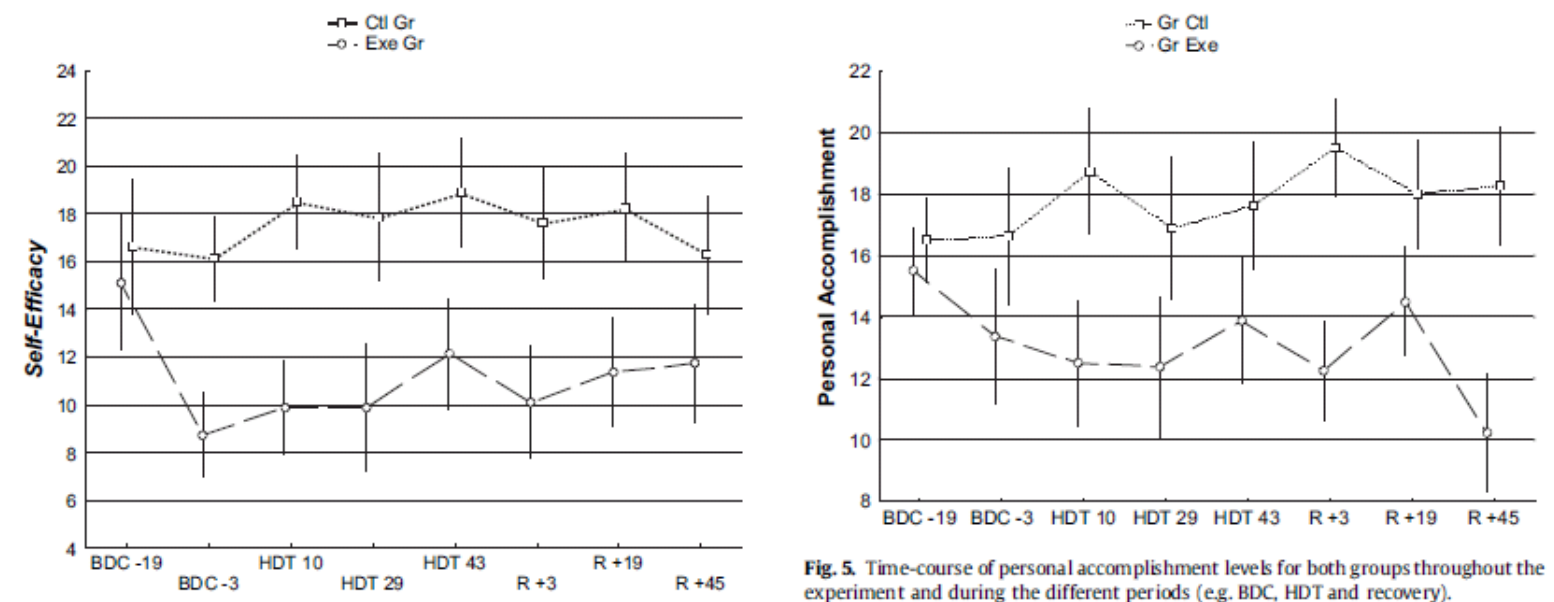

Fig 3. Time-course of levels of self-efficacy for both groups throughout the experiment and during the different periods (e.g. BDC, HDT and recovery).

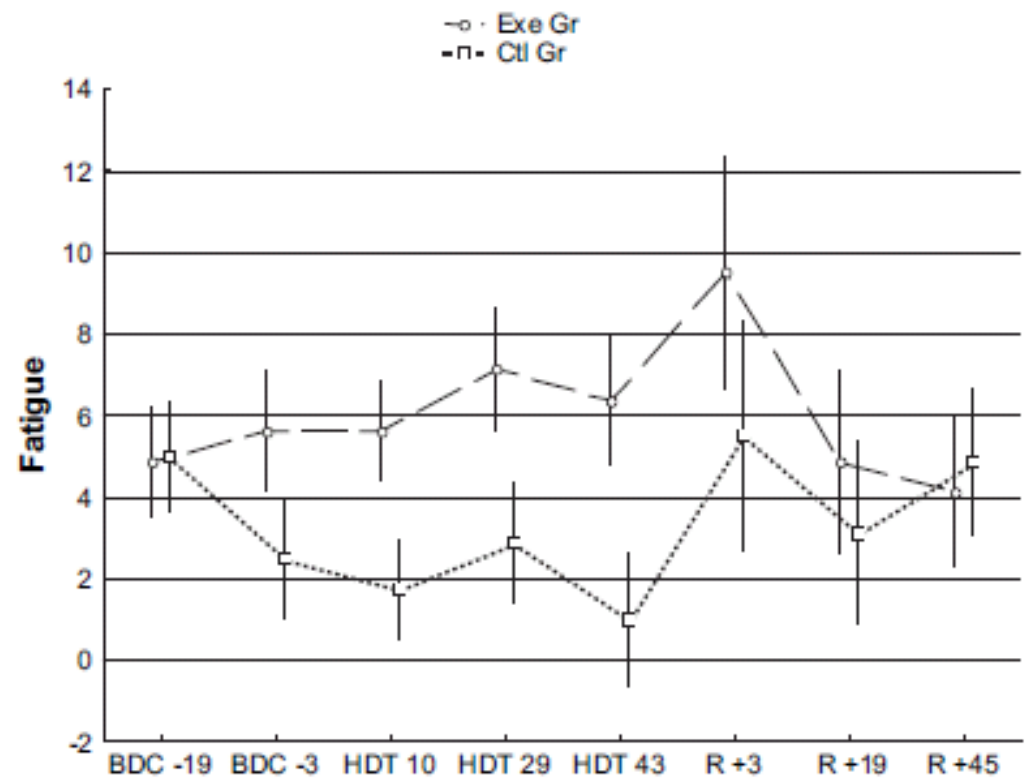

Fig 4. Time-course of levels of fatigue for both groups throughout the experiment and during the different periods (e.g. BDC, HDT and recovery). 
A major interest of this study is the multidimensional assessment of the stress and recovery responses. During HDT, the Exe group had significantly higher scores than the Ctl group on injury and fatigue stress scales. As indicated by the injury scale that consists of any statements dealing with injuries and an impairment in physical capacity, and the fatigue scale that deals with pressure and being disturbed during exercise as well as overfatigue, these physical stress-recovery scales showed that exercise is experienced with difficulty by the exercisers. In addition, the recovery scales, physical recovery and general well-being were lower in the Exe group, showing a recovery deficit in the exercisers compared to the non-exercisers. During the recovery phase, the Exe group again reported higher scores on the Lack of energy stress-related scale, characterized by a lack of energy and an inability to concentrate, and in decision-making. For the follow-up measure ( $R$ p45), the Exe group reported a lower level in personal accomplishment compared to the control group. This suggests that they enjoyed their experience less than the control group.

Thus and surprisingly, exercise did not reduce HDT effects on stress and recovery states. On the contrary, the exercise program had the opposite effect of the hypothesis made in the present study. Effectively, the present findings point out that supine treadmill exercise with lower-body negative pressure (LBNP) combined with post-exercise resting LBNP did not diminish stress states and did not improve recovery states as expected, but conversely the stress level increased and recovery was impaired. However, no previous research using countermeasures based on microgravity-induced changes has clearly and effectively proved to counteract the impaired effects of bed rest on psychological factors. During a 20-day HDT with male participants, exercise training did not modify the increase in impaired mood states and levels of depression provoked by HDT-induced changes (Ishizaki et al., 2002). This is in agreement with another experiment, a 30-day HDT also conducted with male subjects, that showed slight deleterious changes in psychological states which were not improved by exercise training (DeRoshia \& Greenleaf, 1993). Furthermore, results in the Exe group indicated a decline in the activation scale which was attributed to overtraining by the authors. However, the WISE-2005 study had some specificities which might moderate the effects of exercise on psychological states.

First, the Self-Efficacy recovery scale which measures the level of expectation and competence regarding physical performance was higher for the exercisers for the second evaluation after the familiarization sessions of exercise countermeasure. This scale related to exercise activity indicates that the exercisers did not feel that they were doing their physical exercises well and were not achieving their goals successfully, which is shown by a significant reduction in self-efficacy between the two pre HDT measurements for Exe participants. This discrepancy would show the apprehension felt by the Exe participants in facing their exercise tasks before the HDT phase, especially since these differences disappeared between the groups during the HTD phase. Second, the training program was particular, with an aerobic treadmill and resistance fly-wheel exercises, while DeRoshia and Greenleaf (1993) used a different exercise-training regimen with a combination of isotonic and isokinetic exercises. Third, the duration of the present experiment was at least twice as long as previous ones which lasted from 20 to 30 days. Last but not least, the participants in our study were exclusively women. However, very little if no data exist on stress and recovery responses to LTBR in women. In spite of this gender difference, when the available data on men in LTBR is compared, the general trends are quite 
similar with a global increase in stress and no compensatory effect of exercise. The physiological findings during the WISE-2005 experiment suggested that if the combination of resistive and aerobic exercise did not prevent bone resorption, it promoted bone formation, and then helped mitigate the net bone loss associated with simulated microgravity (Smith et al., 2008). Aerobic and resistive exercise prevented changes in cardiovascular responses and was an effective countermeasure to the HDBR effects (Edgell et al., 2007).

Furthermore, the aerobic and resistance exercise protocol was effective in preventing thigh muscle volume loss, and thigh and calf muscle strength loss (Trappe, Burd, Louis, Lee, \& Trappe, 2007). Despite the positive effects of exercise concerning physiological aspects, further improvement of exercise on a psychological level may be conceivable by involving the participants in the exercise program. Adherence to the exercise program has been shown to be important on the outcome of exercise, particularly for alleviating impaired psychological states (Craft, 2005). Previous studies have also found that involvement is an important moderator of exercise issues (Landers \& Arent, 2001; Mutrie, 2000). In addition, knowing that deviations from the recovery-stress balance may lead to failure in adaptation, the function of the recovery activity is to restore balance in order to support the individual's adaptation to potentially stressful situations. To optimize adaptation in extreme situations, stress and recovery states should be addressed in order to monitor the balance between these states. Recovery activities based on individual preferences and fully integrated in the schedule of any program should be planned, as in the workload exercise program. Likewise, the importance of leisure time and distraction should not be ignored, especially in tedious and repetitive situations. Distraction has been shown to be important on the outcome of exercise on the beneficial effects on psychological states (Gleser \& Mendelberg,1990; Leith,1994). Distraction refers to a response style that engages the individual in other activities in order to focus on different thoughts rather than on worries, anxiety and depressed mood (Craft, 2005). A recent study in simulated microgravity has shown that the implementation of game autonomously contributed to positive effects on mental health among the participants (Ishizaki, Fukukoa, Ishizaki, Tanaka, \& Ishitobi, 2004). We believe that these preventive measures may help to obtain a positive outcome of exercise on psychological states in simulated weightlessness as well as in spaceflights.

\section{Conclusion}

The results of the present study offer additional insights to previous research on HDT effects on psychological factors. They mainly suggest that HDT could induce impairments in psychological states, leading to subsequent alterations in stress and decreases in recovery states. If there is evidence to suggest that the combination of resistive and aerobic exercises may be effective in reducing physiological symptoms induced by long-term HDT, the psychological disorders were unfortunately not improved by the exercise program which did not seem to provide an efficient psychological countermeasure.

This investigation contributes to the knowledge of psychological factors which are much less studied than the physiological ones. Stress and recovery dimensions are of major importance for experiments of long duration such as simulating weightlessness in bed rest and are particularly advantageous for the environment of 
manned spaceflights of long duration. As previously suggested, further improvement in positive psychological effects may be possible by involving the participants to insure their adherence to the exercise program; by including a relative dose response relationship between duration, frequency and intensity of exercise countermeasures which would be sufficient to protect muscles and bones and to preserve the cardiovascular system, and, at the same time, would avoid overloading in a balance of recovery-stress states; and by individualizing exercise programs and closely monitoring the participants. In the perspective of spaceflights of long duration such as the future missions to Mars, there is a need for additional experiments to further investigate spaceflight-induced changes of stress and recovery parameters and the effects of exercise on these parameters, not only to determine and analyze the psychological factors involved, but also to intervene concerning these factors with efficient psychological preparation which, although not yet fully investigated, may reduce stress, promote recovery and support adaptive responses to such extreme environments.

\section{Acknowledgements}

The WISE-2005 study was sponsored by the European Space Agency (ESA), the National Aeronautics and Space Administration of the USA (NASA), the Canadian Space Agency (CSA) and the French "Centre National d'Etudes Spatiales" (CNES) which promoted the study in accordance with French law. The study was carried out by MEDES, the Institute for Space Physiology and Medicine in Toulouse, France.

We are especially grateful to the participants of the study and to all the teams and investigators whose "good mood" was affirmed throughout the study period. We thank the MEDES bed rest team and the medical monitors for their invaluable assistance and help in the administration of the tests, with special thanks to Drs. M.P. Bareille and A. Beck.

\section{Appendix. Supplementary data}

Supplementary data associated with this article can be found, in the online version, at doi:10.1016/j.jenvp.2009.08.006

\section{References}

Cao, P., Kimura, S., Macias, B. R., Ueno, T.,Watenpaugh, D. E., \& Hargens, A. R. (2005). Exercise within lower body negative pressure partially counteracts lumbar spine deconditioning associated with 28-day bed rest. Journal of Applied Physiology, 99, 39-44.

Chatelier, S. (2003). Validation française du RESTQ-Sport à partir de la méthodologie de validation de Vallerand. Lyon: Me'moire de Maı^trise STAPS.

Choukèr, A., Thiel, M., Baranov, V., Meshkov, D., Kotov, A., Peter, K., et al. (2001). Simulated microgravity, psychic stress, and immune cells in men: observations during 120-day 6_HDT. Journal of Applied Physiology, 90, 1736-1743.

Craft, L. L. (2005). Exercise and clinical depression: examining two psychological mechanisms. Psychology of Sport and Exercise, 6, 151-171. 
Daley, A., \& Welch, A. (2004). The effects of $15 \mathrm{~min}$ and $30 \mathrm{~min}$ of exercise on affective responses both during and after exercise. Journal of Sports Science, 22(7), 621-628.

DeRoshia, C. W., \& Greenleaf, J. E. (1993). Performance and mood-state parameters during 30-day 6 degrees head-down bed rest with exercise training. Aviation Space and Environmental Medicine, 64(6), 522-527.

Edgell, H., Zuj, K. A., Greaves, D. K., Shoemaker, J. K., Custaud, M. A., Kerbeci, P., et al. (2007). WISE-2005: adrenergic responses of women following 56-days, 6 degrees head-downbed rest with or without exercise countermeasures.American Journal of Physiology - Regulatory, Integrative and Comparative Physiology, 293(6), 2343-2352.

Filaire, E., Bernain, X., Sagnol, M., \& Lac, G. (2001). Preliminary results on mood state, salivary testosterone: cortisol ratio and team performance in a professional soccer team. European Journal of Applied Physiology, 86, 179-184.

Gleser, J., \& Mendelberg, H. (1990). Exercise and sport in mental health: a review of the literature. Israel Journal of Psychiatry and Related Sciences, 27, 99-112.

Grigorév, A. I., \& Fedorov, B. M. (1996). Stress under normal conditions, hypokinesia simulating weightlessness, and during flights in space. Human Physiology, 22(2), 139-147.

Gushin, V. I. (1995). Problems of psychological control in prolonged space flight. Earth Space Review, 4(1), 28-33.

Hansen, C. J., Stevens, L. C., \& Coast, J. R. (2001). Exercise duration and mood state: how much is enough to feel better? Health Psychology, 20(4), 267-275.

Harrison, A. A. (2005). Behavioral health: integrating research and application in support of exploration missions. Aviation, Space, and Environmental Medicine, 76(6), B3-B12.

Ishizaki, Y., Fukuoka, H., Ishizaki, T., Tanaka, H., \& Ishitobi, H. (2004). The implementation of game in a 20-day head-downtilting bed rest experiment uponmood status and neurotic levels of rest subjects. Acta Astronautica, 55(11), 945-952.

Ishizaki, Y., Fukuoka, H., Katsura, T., Nishimura, Y., Kiriyama, M., Higurashi, M., et al. (1994). Psychological effects of bed rest in young healthy subjects. Acta Physiologica Scandinavica, 150(Suppl. 616), 83-87.

Ishizaki, Y., Ishizaki, T., Fukuoka, H., Kim, C. S., Fujita, M., et al. (2002). Changes in mood status and neurotic levels during a 20-day bed rest. Acta Astronautica, 50(7), 453-459.

Johnson, M. S.,Wrisberg, C. A., Kellmann, M., \& Kallus, K. W. (1997). Assessing stress and recovery in collegiate athletes. Journal of Applied Sport Psychology, 8, S113. 
Kanas, N., \& Manzey, D. (2003). Space psychology and psychiatry. Dodrecht: Springer, Kluwer Academic Press.

Kellmann, M., \& Gu" nther, K. D. (2000). Changes in stress and recovery in elite rowers during preparation for olympic games. Medicine and Science in Sports and Exercise, 32, 676-683.

Kellmann, M., \& Kallus, K.W. (1993). The recovery-stress-questionnaire: a potential tool to predict performance in sports. In J. R. Nitsch, \& R. Seiler (Eds.), Movement and sport: Psychological foundations and effects (pp. 242-247). Sankt Augustin: Academia.

Kellmann, M., \& Kallus, K. W. (2001). Recovery-stress questionnaire for athletes. Champaign, IL: Human Kinetics.

Kellmann, M., Kallus, K. W., Steinacker, J. M., \& Lormes, W. (1997). Monitoring stress and recovery during the training camp for the junior world championships in rowing. Journal of Applied Sport Psychology, 9, S114.

Landers, D. M., \& Arent, S. M. (2001). Physical activity and mental health. In R. N. Singer, H. A. Hausenblaus, \& C. Janelle (Eds.), The handbook of research in sport psychology (2nd ed.). (pp. 740-765) New York: Wiley.

Lathers, C. M., \& Charles, J. B. (1994). Comparison of cardiovascular function during the early hours of bed rest and space flight. Journal of Clinical Pharmacology, 34, 489-499.

Leith, L. M. (1994). Foundations of exercise and mental health. Morgantown, WV: Fitness Information Technology.

Leon, G. R. (2005). Men and women in space. Aviation, Space, and Environmental Medicine, 76(6), B84-B88.

Louisy, F., Berry, P., Marini, J. F., Guell, A., \& Guezennec, C. Y. (1995). Characteristics of the venous hemodynamics of the leg under simulated weightlessness: effects of physical exercise as countermeasure. Aviation, Space, and Environmental Medicine, 66, 542-549.

Mutrie, N. (2000). The relationship between physical activity and clinically defined depression. In S. J. H. Biddle, K. Fox, \& S. H. Boutcher (Eds.), Physical activity and psychological well-being (pp. 46-62). London: Routledge.

Nabkasorn, C., Miyai, N., Sootmongkol, A., Junprasert, S., Yamamoto, H., Arita, M., et al. (2006). Effects of physical exercise on depression, neuroendocrine stress hormones and physiological fitness in adolescent females with depressive symptoms. The European Journal of Public Health, 16(2), 179-184.

Nicolas, M., Thullier-Lestienne, F., Bouquet, C., Gardette, B., Gortan, C., Joulia, F., et al. (1999). An anxiety, personality and altitude symptomatology study in individuals 
participating in a 31-day period of hypoxia in a hypobaric chamber (experiment "Everest-Comex 1997"). Journal of Environmental Psychology, 19(4), 407-414.

Otto, J. (1990). The effects of physical exercise on psychophysiological reactions under stress. Cognition and Emotion, 5, 341-357.

O'Halloran, P. D., Kirkby, R., \& Webster, K. E. (2001). Mood changes during exercise. Australian Journal of Primary Health - Interchange, 7(2), 24-31.

Palinkas, L. A., \& Suedfeld, P. (2007). Psychological effects of polar expeditions. The Lancet, 369, 1-11.

Parfitt, G., \& Gledhill, C. (2004). The effect of choice of exercise mode on psychological responses. Psychology of Sport and Exercise, 5, 111-117.

Ritsher, J. B., Kanas, N. A., Ihle, E. C., \& Saylor, S. A. (2007). Psychological adaptation and salutogenesis in space: lessons from a series of studies. Acta Astronautica, 60, 336-340.

Rosnet, E., Jurion, S., Cazes, G., \& Bachelard, C. (2004). Mixed-gender groups: coping strategies and factors of psychological adaptation in a polar environment. Aviation, Space, and Environmental Medicine, 76(6), C10-C13.

Rowbottom, D. G., Keast, D., \& Morton, A. R. (1998). Monitoring and preventing of overreaching and overtraining in endurance athletes. In R. B. Kreider, A. C. Fry, \& M. L. O'Toole (Eds.), Overtraining in sport (pp. 47-66). Champaign, IL: Human Kinetics.

Salmon, P. (2001). Effects of physical exercise on anxiety, depression, and sensitivity to stress - a unifying theory. Clinical Psychology Review, 21(1), 33-61.

Smith, S. M., Zwart, S. R., Heer, M., Lee, S. M., Baecker, N., Meuche, S., et al. (2008). WISE-2005: supine treadmill exercise within lower body negative pressure and flywheel resistive exercise as a countermeasure to bed restinduced bone loss in women during 60-day simulated microgravity. Bone,

42(3), 572-581.

Sonnenfeld, G., Aviles, H., Butel, J. S., Shearer, W. T., Niesel, D., Pandya, U., et al. (2007). Bed rest and immunity. Acta Astronautica, 60, 234-236.

Steinacker, J. M., Lormes,W., Kellmann, M., Liu, Y., Reissnecker, S., Opitz-Gress, A., et al. (2000). Training of junior rowers before world championships. Effects on performance, mood state and selected hormonal and metabolic responses. Journal of Sports Medicine and Physical Fitness, 40, 327-335.

Styf, J. R., Hutchinson, K., Carlsson, S. G., \& Hargens, A. R. (2001). Depression, mood state, and back pain during microgravity simulated by bed rest. Psychosomatic Medicine, 63, 862-864. 
Suedfeld, P. (1998). What can abnormal environments tell us about normal people? Polar stations as natural psychology laboratories. Journal of Environmental Psychology, 18, 95-102.

Suedfeld, P. (2005). Invulnerability, coping, salutogenis, integration: four phases of space psychology. Aviation, Space, and Environmental Medicine, 76(6), B61-B66. Trappe, T. A., Burd, N. A., Louis, E. S., Lee, G. A., \& Trappe, S. W. (2007). Influence of concurrent exercise or nutrition countermeasures on thigh and calf muscle size and function during 60 days of bed rest in women. Acta Physiologica, 191(2), 147-159.

Trappe, S., Trappe, T., Gallagher, P., Harber, M., Alkner, B., \& Tesch, P. (2004). Human single muscle fibre function with 84-day bed rest and resistance exercise. Journal of Physiology, 557(2), 501-513.

Weiss, K., \& Moser, G. (1998). Interpersonal relationships in space simulation: the long-term bed rest in head-down tilt position. Acta Astronautica, 43(3-6), 235-248. 